\title{
La construcción de ciudades en ladera. Movilidad urbana: Getaria
}

\author{
Maria Iceta Etxabe \\ Área de Conocimiento Urbanística y Ordenación del Territorio, Departamento de Arquitectura, \\ Universidad del País Vasco, Donostia/San Sebastián, España. \\ E-mail:maria.iceta@ehu.eus
}

\begin{abstract}
Resumen. En el proceso de proyección y construcción del territorio y del paisaje en el contexto de Gipuzkoa las futuras expansiones urbanas se van a asentar a medio-largo plazo sobre terrenos periféricos de difíiles condiciones topográficas. Este trabajo de investigación pretende redescubrir los parámetros conceptuales, proyectuales y constructivos aplicados en experiencias urbanizadoras ya consolidadas con éxito.

La metodología se ha basado en el análisis de la intervención del ser humano a lo largo de la historia de la civilización por diferentes culturas sobre complejas condiciones geográficas y topográficas en aras de transformar el paisaje natural para generar con racionalidad suelo apto para actividades agrícolas y productivas, así como para la proyección, urbanización y construcción de ciudades en orografias accidentadas, mediante el estudio de las catacterísticas morfológicas, estructurales y constructivas. Se expone el estudio y análisis realizado sobre la villa de Getaria, los procesos de transformación paisajística a distintas escalas en diversos contextos con medios tecnológicos variados desde su fundación hasta este último siglo.

El objetivo es descubrir la lógica proyectual de las intervenciones urbanas, infraestructurales y edificatorias ejecutadas en el tiempo y proponer las claves básicas de intervención en el proceso de urbanización y construcción del territorio y del paisaje en ladera.
\end{abstract}

Palabras clave: Construcción en ladera, territorio, arquitectura, estructura urbana, paisaje, movilidad urbana.

\section{La construcción de una ciudad racional en vaguada: Getaria.}

El territorio y el paisaje natural se transforman por la acción del ser humano y surgen nuevos paisajes. Aquellos territorios de topografía accidentada condicionan el asentamiento y la construcción de la ciudad. El proyecto de una ciudad en terrenos en pendiente, a media ladera, en la vaguada de un valle o en el promontorio de una colina, debe ahondar en las características morfológicas del territorio. A lo largo de la historia, el medio natural ha sido transformado por el ser humano para explotar los recursos que la tierra origina. En el hábitat rural con escasos recursos técnicos y el conocimiento basado en la observación, se ha domesticado el suelo y cultivado la tierra para obtener alimentos vegetales. En el urbano las ciudades racionales se han construido con un proyecto previo, en el que se describe una idea de ciudad que define la estructura y la forma urbana. La técnica constructiva para geometrizar el territorio y conseguir plataformas se ha basado en muros y rellenos o en pilares y forjados, que permiten el aprovechamiento doble del espacio.

Getaria es una villa medieval asentada en la acantilada costa guipuzcoana que se escabulle en el mar y en el que el pequeño puerto refugio, al resguardo del monte San Antón, contribuyó 
a la vocación marinera que la caracteriza. El relieve ha condicionado la construcción de bancales agrícolas, destinados a viñedos principalmente, y también la implantación de la malla racional que ha permitido la utilización del espacio para usos urbanos, residenciales, actividades productivas y el esparcimiento. Fundada en el siglo XIII, el centro urbano compacto se estructura en torno a un sistema de calles paralelas, escalonadas, adaptadas a las curvas de nivel y cantones transversales. El proceso de urbanización y preparación de suelo se adecuó a las demandas infraestructurales y constructivas. La geometrización de la forma natural del territorio en base a desmontes y muros de contención permitió la creación de unos canales para el trazado viario, cuatro calles longitudinales de norte a sur, adaptadas a la topografía conforman plataformas escalonadas en las que se lotizan los solares edificables.

Atendiendo a la forma de implantación de la malla que caracteriza el tejido urbano propio de cada ciudad surgen ciudades estructuradas en torno a un sistema de calles lineales o circulares, paralelas, escalonadas y adaptadas a las curvas de nivel y cantones transversales como Berna, o Vitoria/Gasteiz; ciudades estructuradas en base a una malla-retícula viaria impuesta sobre la topografía natural de la ladera, es el ejemplo de Priene; ciudades estructuradas en torno al cruce de dos ejes ortogonales trazados contra la pendiente del territorio, tal es el caso de la bastida de Monflanquin; y ciudades estructuradas en torno a un eje viario principal trazado en la línea de cresta de la colina como Edimburgo, o en el fondo de una vaguada del que emergen calles ortogonales de menor entidad como Dubrovnik. Con la clasificación realizada según la morfología urbana, Getaria se identifica con las ciudades del primer grupo descrito.

En el interior de la trama urbana medieval, en las áreas de mayor dificultad topográfica los espacios públicos abiertos y monumentos principales se adecúan a las necesidades sociales y culturales, como la Iglesia gótica de Getaria, bajo la cual transcurre la calle Mayor, y se prolonga bajo el pasadizo para llegar al puerto en el que se refugiaban las embarcaciones pesqueras y mercantes.
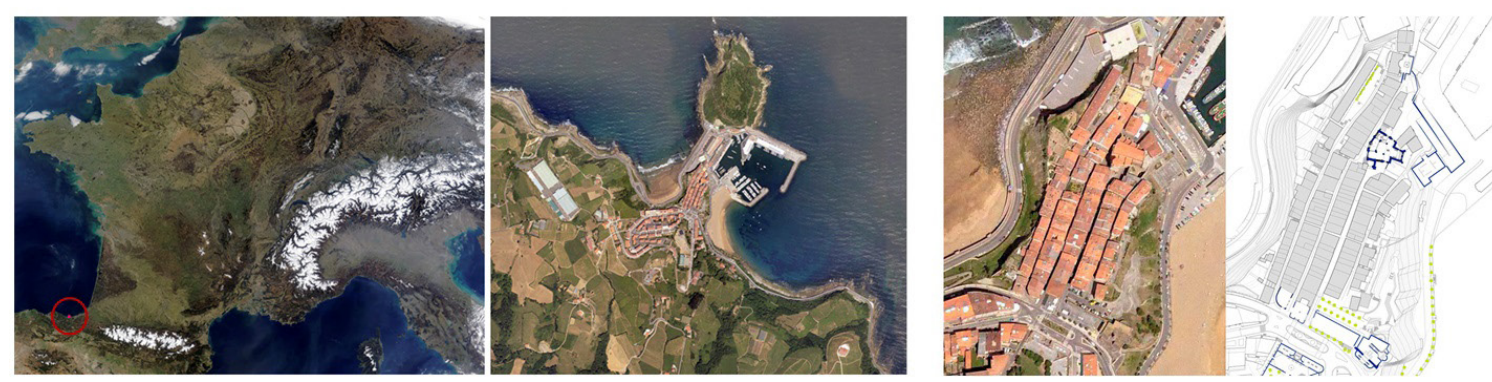

Fig. 1. Getaria. Situación y emplazamiento.
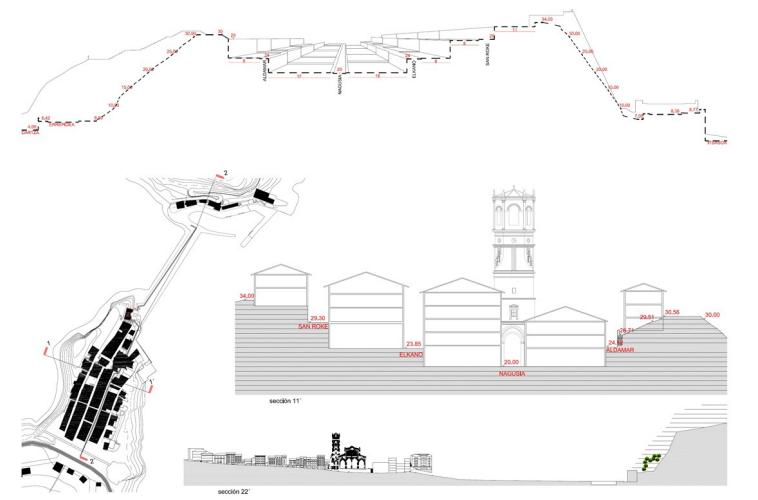

Fig. 2. Getaria: la geometrización del territorio. Sección transversal y longitudinal a través de la calle Mayor.

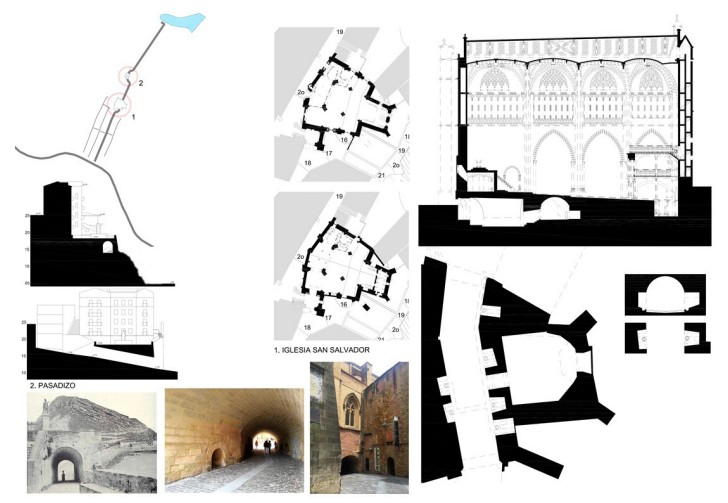

Fig. 3. Pasadizo y la Iglesia San Salvador insertados en el tejido urbano que se adecúa a la orografía. Arquitecto autor del levantamiento de la Iglesia: Ramón Ayerza. 


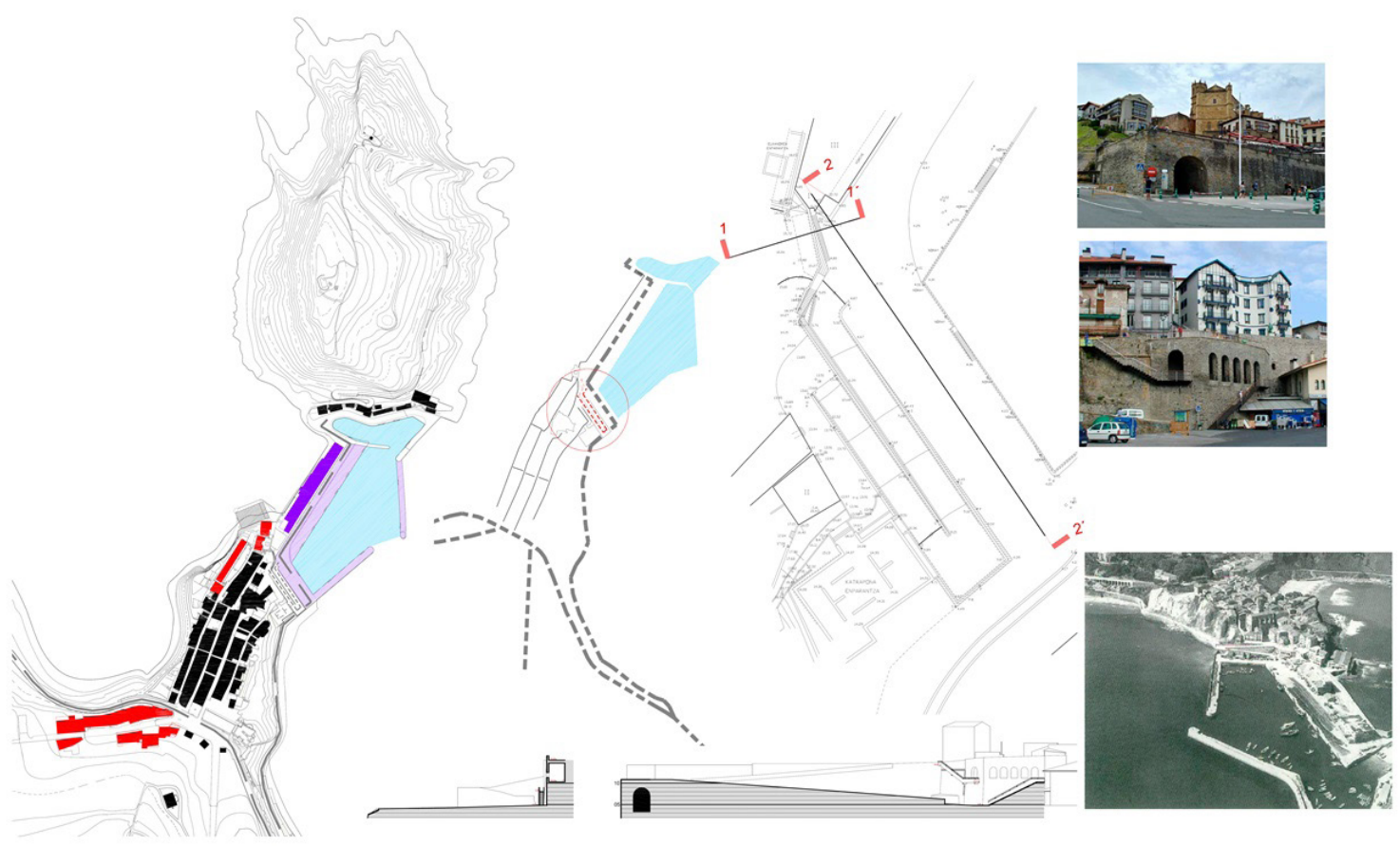

Fig. 4. Refuerzo de la conexión peatonal desde el frente de mar hasta la ciudad asentada a una altitud de $17 \mathrm{~m}$. creando itinerarios alternativos hacia el puerto ampliado.

\section{Tráfico rodado.}

La llegada a partir de la segunda mitad del siglo XIX del automóvil trajo unos cambios formales y estructurales urbanos por las transformaciones que requerían las nuevas formas de movilidad. El desarrollo de la infraestructura viaria permitió el salto de la ciudad al frente de mar.

En Getaria se construyeron dos ramales viarios en los acantilados situados al este y oeste del núcleo medieval, cerrando un anillo con la carretera de la costa. Con ello se mejoró sustancialmente la actividad pesquera del puerto cuya lámina de agua se extendió tras las ampliaciones de los años 1919 y 1953, y que culminaron con la construcción del dique iniciada el año 1977 para proteger de los embates del mar, así como con las obras de dragado para la ampliación de la bocana y el calado.

Las obras de ingeniería con la construcción de vías de comunicación modernas han permitido superar las dificultades que plantean las características geológicas de esta orografía accidentada, domesticando la naturaleza; las laderas rocosas, y el mar. A su vez, mediante estas actuaciones se crearon dos playas, en cada una de las orientaciones surcadas por la infraestructura viaria, impulsando otra actividad económica, la terciaria, enfocada hacia el turismo.

Similares actuaciones a las presentadas se llevaron a cabo en otras ciudades portuarias, en contextos similares, también asentadas en ladera, como en Mao (Menorca), cuando un nuevo eje rodado con un trazado sinuoso se ubicó en una vaguada marginal como alternativa a unas rampas para peatones y carruajes existentes a ambos márgenes del centro histórico.

\section{Articulación entre las nuevas expansiones urbanas en ladera.}

Paralelamente a las obras de ampliación de la infraestructura portuaria se incorporaron nuevos fragmentos urbanos en la expansión de la ciudad hacia el sur, ascendiendo las laderas, alrededor de dos ejes orientados hacia el suroeste y sureste. La accesibilidad fue abordada mediante la solución de viales rodados de acceso a cotas altas articulando el mayor número de conjuntos urbanos, reduciendo en lo posible los sucesivos meandros, y completando la trama de la ciudad 


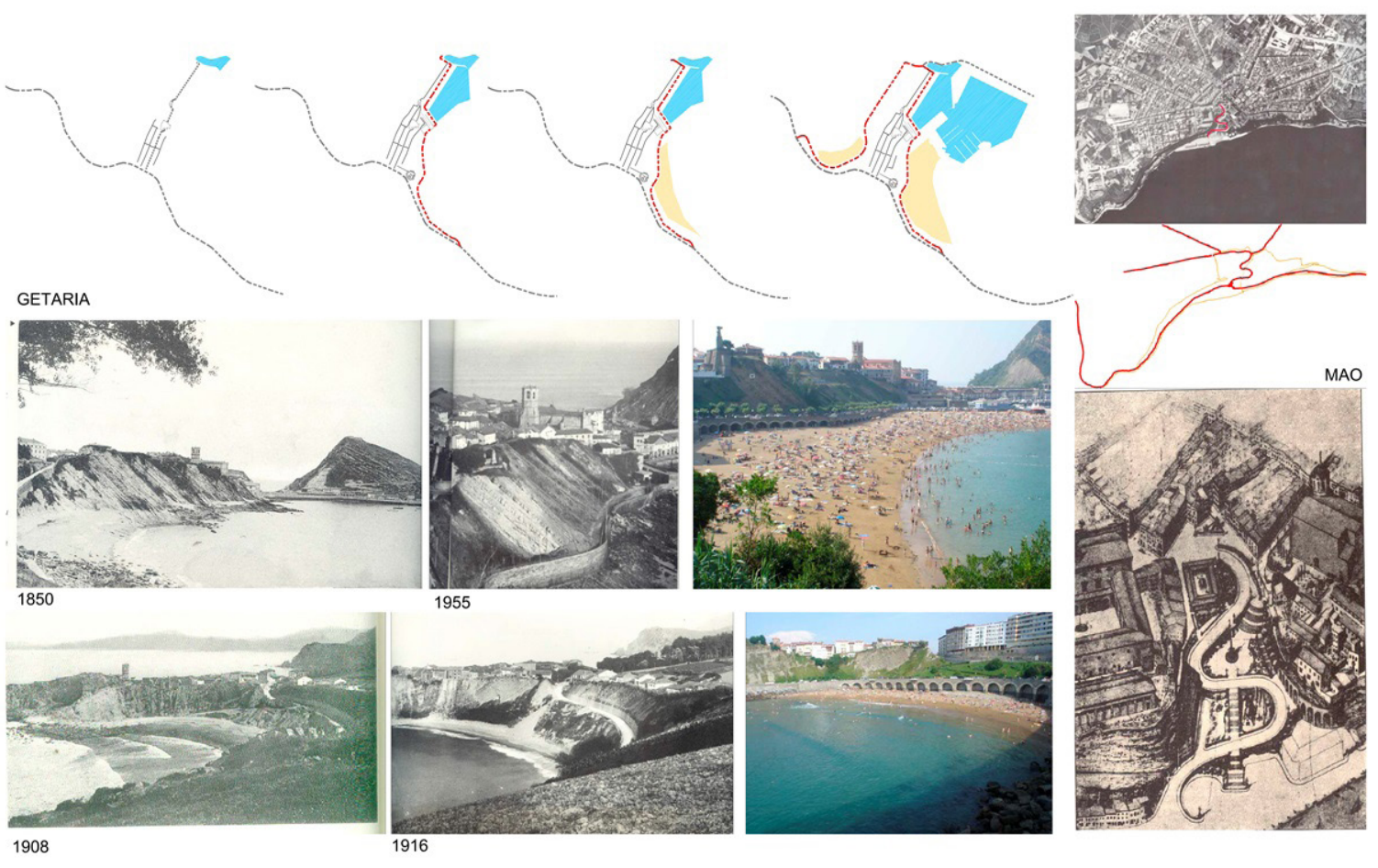

Fig. 5. Evolución de la infraestructura viaria en Getaria: ladera este (1850, 1955 y en la actualidad) y ladera oeste (1908, 1916 y en la actualidad) y en Mao (Menorca).

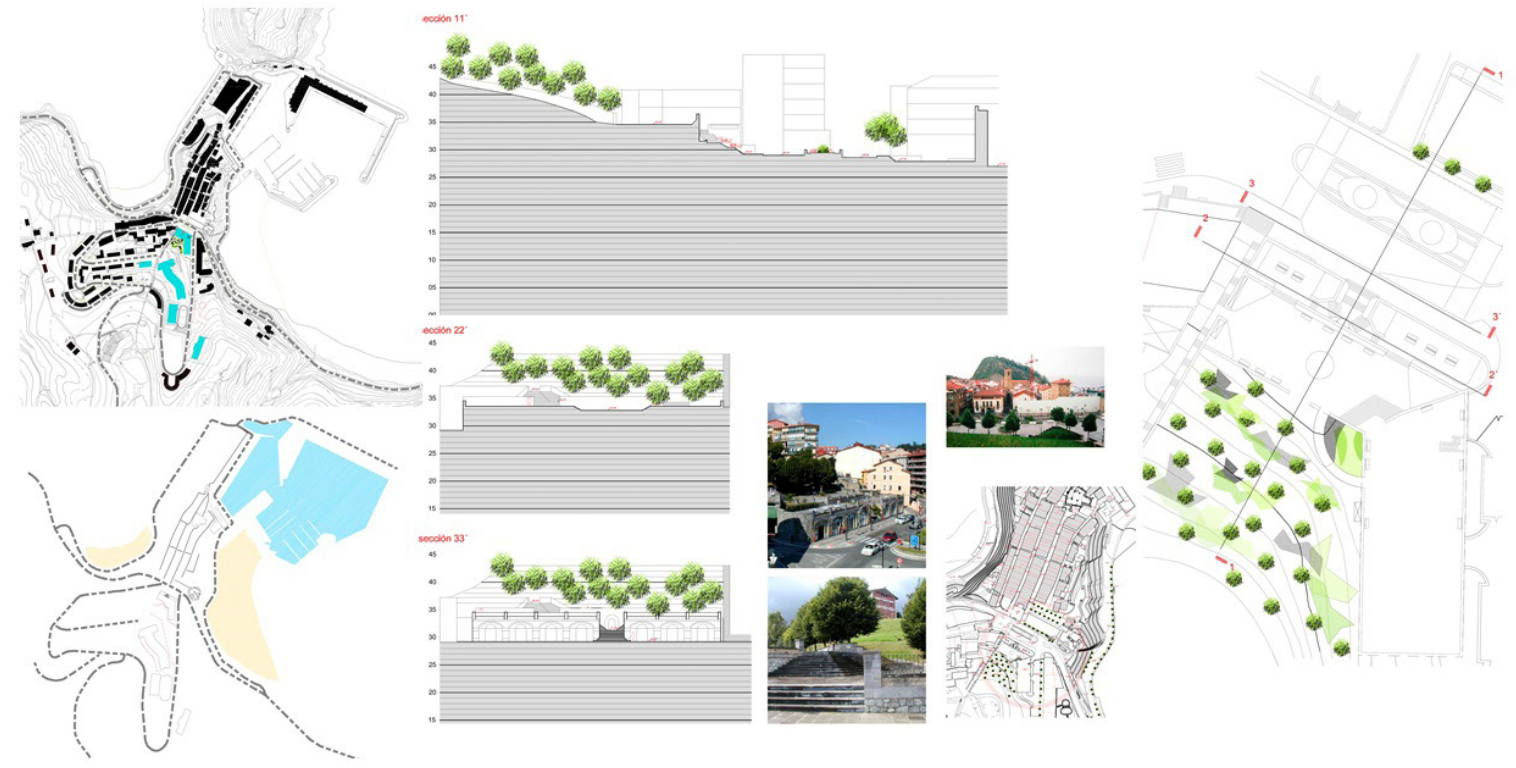

Fig. 6. Dotaciones públicas articulando las nuevas expansiones urbanas en ladera.

ampliada mediante rampas o escaleras que permiten la conexión transversal.

Se consideran de gran interés las intervenciones que han permitido el cosido transversal, a distintos niveles de los fragmentos residenciales que han ido colonizando las cotas superiores siguiendo la directriz de los dos ejes mencionados. El carácter dotacional, público, de los diversos usos a los que se destinan las plataformas intermedias ha permitido la cohesión de las dos vaguadas.

Destacan en el primer nivel, la explanada a cota $+34,00 \mathrm{~m}$. destinada a plaza-parque, como lugar de recreo, con un espacio inferior, 
bajo la plataforma, con uso de aparcamiento. El nivel superior como plaza está dotada de espacios para el juego, reposo, con pequeños muretes que se van adecuando a la forma del territorio y la vegetación aporta variadas texturas a lo largo del año dotando de un paisaje cambiante. A una altura de $+44,00 \mathrm{~m}$. se asienta el palacio Aldamar y desde el año 2011, las actuaciones urbanizadoras vinculadas a la construcción del museo erigido en honor al modisto C. Balenciaga han permitido mejorar la comunicación transversal, hacia el este con las instalaciones deportivas municipales, y hacia el oeste con el nuevo edificio al servicio de los ciudadanos, que ofrece asistencia sanitaria y social, a aproximadamente $+51,00$ m. Por último, destaca la intervención proyectada, e iniciada pero aún sin concluir, que rematará la expansión urbana, que alcanza la cota $+75 \mathrm{~m}$., y quedará delimitada mediante bloques destinados a vivienda, junto con el vial transversal que cierra el sector residencial.

Como ejemplos de espacios abiertos generados en intervenciones clásicas sobre terrenos en ladera construidos sobre muros-zócalo de distinta altura se han estudiado el gimnasio y palestra de Priene, y el complejo palatino de Persépolis. Desde los griegos, la estoa ha sido un recurso arquitectónico clásico que ofrece un espacio cubierto para distintos usos. Construido por un muro a un lado, que puede ser de contención, una o dos crujías y con una sucesión de columnas que delimitan el espacio alargado, con respecto al exterior, en uno o dos niveles.

El arte de la jardinería integra elementos naturales, láminas de agua, arbolado, plantaciones vegetales, $o$ pequeñas construcciones $\mathrm{o}$ arcadas para la sombra que pueden ser referentes para definir formalmente $y$ compositivamente nuevos fragmentos enmarcados en espacios urbanos. Se han estudiado concerniente a este tipo de intervenciones en ladera, si bien en otros contextos geográficos y culturales, los jardines del Generalife en Granada, o Sanssouci en Potsdam.

Como ejemplos de articulación de la arquitectura con fragmentos urbanos se citan el edificio de juzgados en Canyeret (Lleida) de Ll. Domenech y R. Amado, y el museo y parque en Cartagena de Rafael Moneo.

\section{La movilidad peatonal.}

El desnivel que alcanza el asentamiento urbano de esta ciudad marinera desde el nivel del mar hasta una altura de $75 \mathrm{~m}$. requiere de una diversidad de elementos de sutura para facilitar la movilidad peatonal. Se han insertado elementos puntuales que han mejorado la accesibilidad en zonas estratégicas articulando

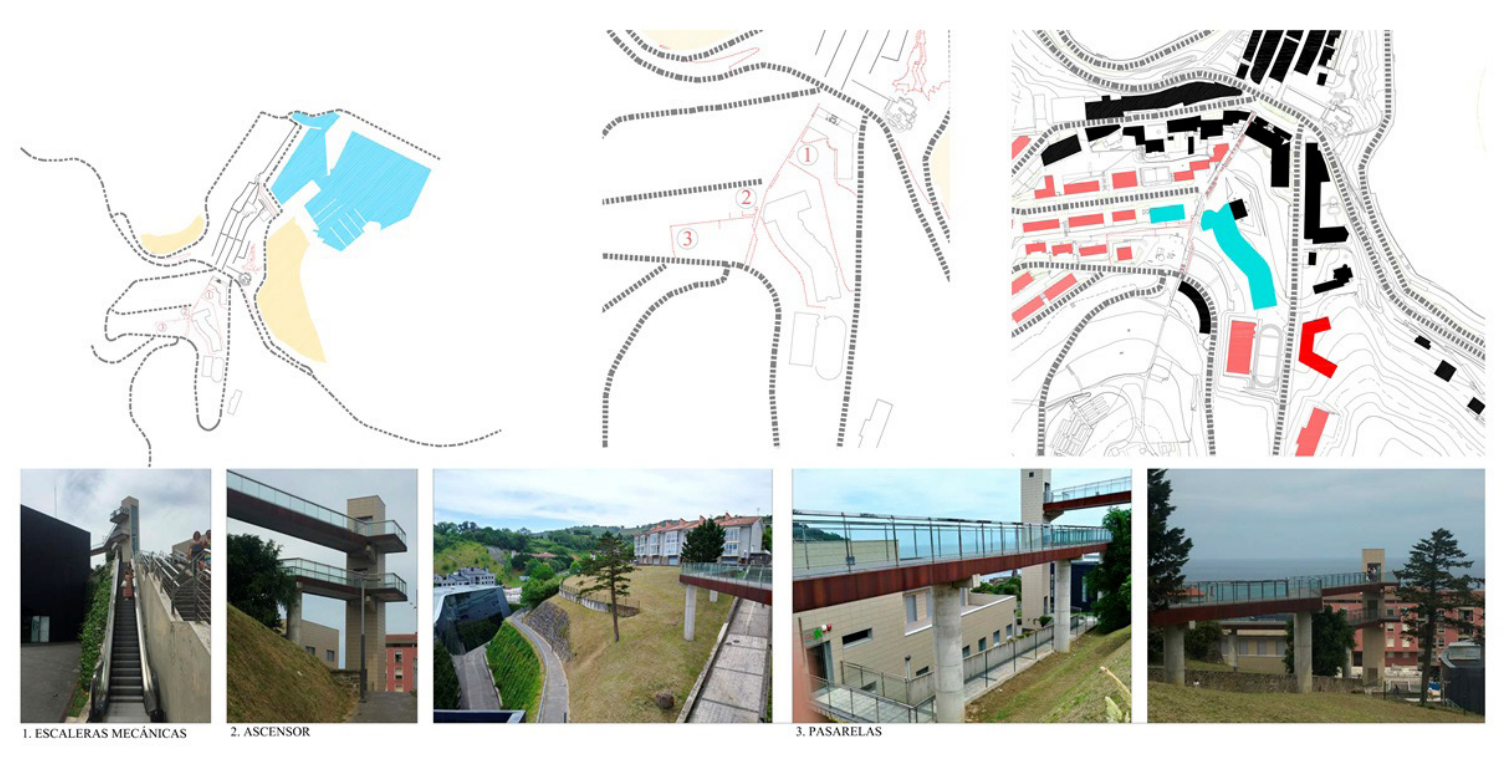

Fig. 7. Elementos que mejoran la movilidad peatonal: escaleras mecánicas (1), ascensor (2) y pasarelas (3). 
el centro histórico con el crecimiento residencial ascendente: escaleras mecánicas, la instalación de un ascensor y pasarelas.

Las escaleras mecánicas en cuatro tramos conectan las distintas plataformas que se han construido en la ladera sur, desde una altura de $+29,00 \mathrm{~m}$. a la que discurre el vial principal, N634 o carretera de la costa con un interés paisajístico notorio, con paradas en la $+34,00$ m. para desembarcar en el parque, y a $+44,00$ $\mathrm{m}$. en el museo Balenciaga, y hasta la $+51,00$ $\mathrm{m}$. a la que se encuentra la dotación social asistencial sanitaria. El ascensor salva un desnivel de casi veinte metros desde $+51,00$ $\mathrm{m}$. hasta $+70,00 \mathrm{~m}$. a la que llega el polígono residencial que actúa como borde urbano en la orientación suroeste. Las pasarelas emergen a distintos niveles intermedios entre el arranque y última parada del ascensor, aproximadamente a cota $+65,00 \mathrm{~m}$., y $+55,00 \mathrm{~m}$. permitiendo el acceso a las distintas plantas del centro asistencial-sanitario.

Además, destacan como filamentos sutiles la construcción de rampas, plataformas, y escaleras apoyadas en los acantilados que hasta poco menos que siglo y medio protegían $\mathrm{y}$ defendían la villa $\mathrm{y}$, sin embargo ahora, permiten el afianzamiento de los elementos que la hacen accesible y permeable desde diversos flancos. Estos elementos de sutura que optimizan la movilidad peatonal están vinculados al trazado de los elementos que
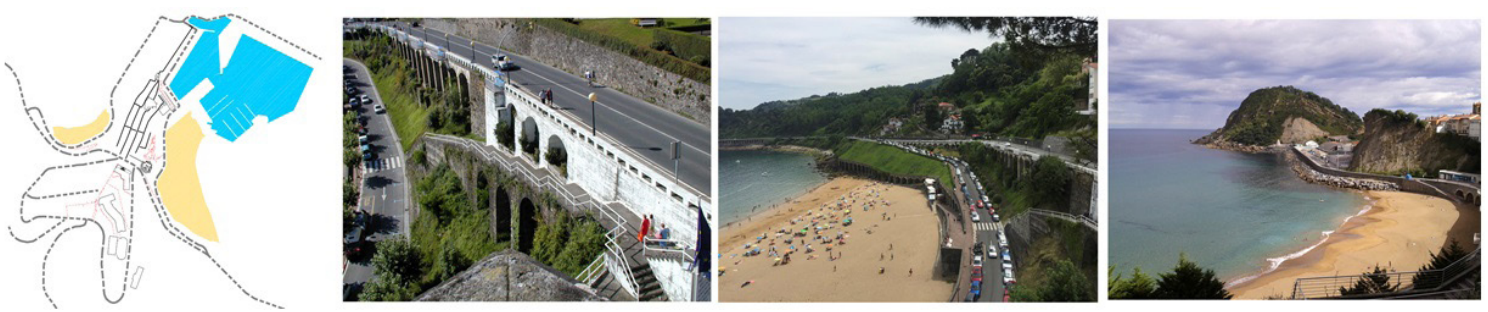

Fig. 8. Filamentos de sutura. Ladera orientada al este: rampas y escaleras. Ladera orientada al oeste: rampa.
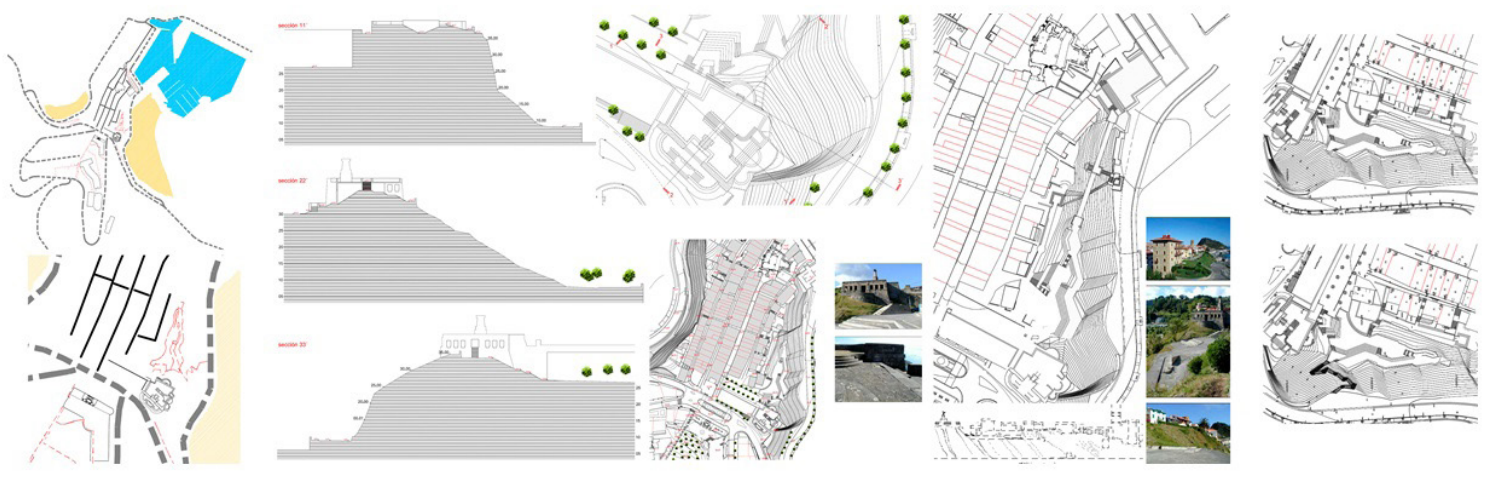

Fig. 9. Disposición de elementos de articulación en el paisaje urbano: plataformas y belvedere.
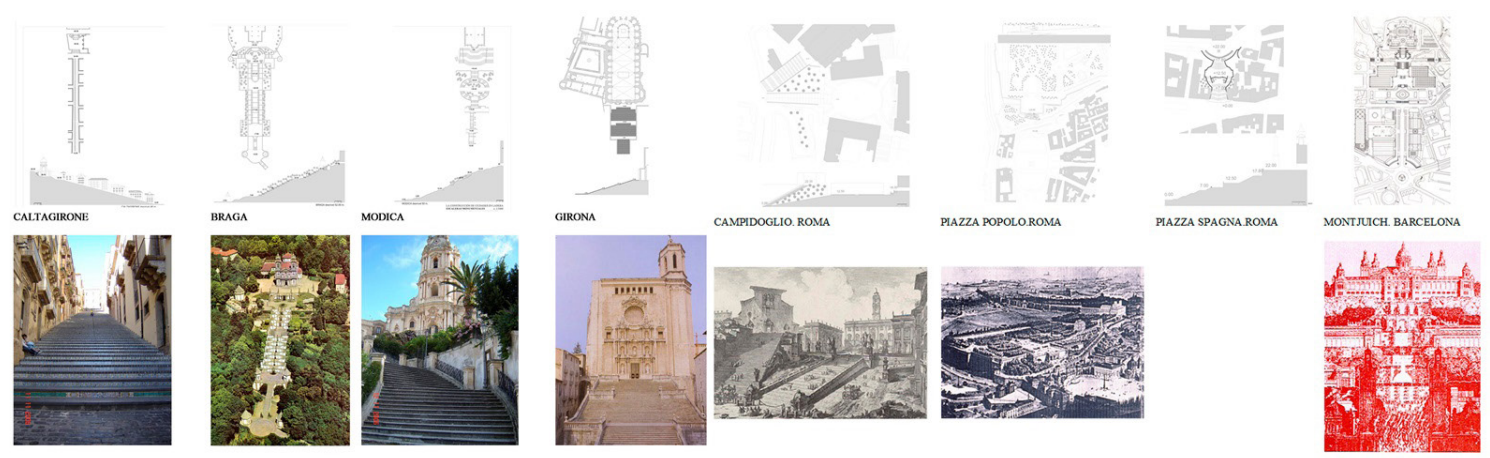

Fig. 10. Procesos de urbanización: accesibilidad y movilidad. Caltagirone, Braga, Módica, Girona, Roma, Barcelona. 
permiten la accesibilidad rodada.

El monumento erigido en memoria a Juan Sebastián de Elkano (1925) en un lugar estratégico, sobre un antiguo baluarte de la muralla, a modo de belvedere, o mirador, es una construcción que a su través se puede disfrutar de las vistas que se abren hacia el atractivo paisaje marítimo. Las plataformas de Vista Ona destacan como lugar de esparcimiento, incompletas pero ideadas también como recorrido elevado, a media ladera, bordeando la costa, que una vez se ultimen desembocarán en la plaza Katrapona asentada sobre la primera infraestructura trazada en aras de mejorar la comunicación entre el puerto y la ciudad. Este proyecto, parcialmente construido, ha sido complementado con la inserción de unas escaleras que relacionan las sucesivas terrazas escalonadas con la playa bajo el acantilado este.

Diversas soluciones de pasarelas, rampas, escaleras urbanas, escalinatas que se han estudiado en el presente trabajo, Roma, Módica, Girona, Caltagirone, etc. reflejan la importancia de recuperar estos elementos infraestructurales.

\section{Conclusión}

Una de las conclusiones de este trabajo de investigación es la necesidad de lograr un equilibrio entre los trazados de las infraestructuras de tráfico rodado y peatonal y la morfología urbana de las ciudades asentadas sobre territorios en ladera. La problemática de la accesibilidad y movilidad rodada y peatonal adquiereinterés en la proyección eincorporación de nuevos fragmentos de territorios en ladera en el proceso de expansión de ciudades. Desajustes morfológicos y estructurales que se observan en los crecimientos urbanos surgen en laderas periféricas por tratarse de actuaciones espontáneas que carecen de una visión integral de proyecto de ciudad basada en la inserción articulada de las infraestructuras del conjunto edificado y de los espacios abiertos en el proyecto de ciudad.

Resulta fundamental resolver la movilidad peatonal con la inserción de filamentos de sutura relacionados con los elementos que permiten la accesibilidad rodada, el sistema viario que estructura la ciudad, cuya disposición está relacionada con las características topográficas y la orografía de cada lugar.

En el caso estudiado, Getaria, se han evitado sucesivos meandros y se ha abordado de manera coherente la construcción racional de la ciudad ampliada y la ciudad re-estructurada. Se han visto dos maneras de afrontar la accesibilidad en ladera en áreas urbanas ya consolidadas en las que se interviene en actuaciones de mejora, así como en las nuevas intervenciones. La primera, mediante la implantación de la malla que caracteriza el tejido urbano propio de cada ciudad atendiendo a su morfología y da origen a solares edificables. La segunda manera es mediante la inserción de elementos estructurantes, que pueden ser actuaciones de mayor envergadura, como la construcción de plataformas construidas sobre pilares para crear espacios diferenciados destinados a diversos usos, o edificios asentados mediante muros que incorporan texturas varias y vegetación en el paisaje urbano, o elementos de sutura, desde las clásicas rampas y escalinatas, pasarelas, hasta las instalaciones mecánicas como los ascensores. Es fundamental la correcta implantación de estos elementos de cosido y articulación que modifican la topografía para crear un paisaje con identidad propia, y además pueden transformarse en espacios para el esparcimiento, o de contemplación, atendiendo a la singularidad de cada lugar.

\section{Agradecimientos:}

Quisiera agradecer muy especialmente a Xabier Unzurrunzaga, catedrático de Urbanismo y Ordenación del Territorio en ETSA (EHU/UPV) con quien me inicié en el trabajo de investigación sobre la construcción del territorio y paisaje en ladera. Lo mejor del trabajo le pertenece.

\section{Referencias}

Busquets i Grau, Joan. 2004. Barcelona: la construcción urbanística de una ciudad compacta. Barcelona: Ediciones del Serbal. Chevalir, Jean-Louis. 1991. Les bastides du 
Périgord. Toulouse: Diagram Editeur.

Manfredi, Valerio Massimo. 2000. Akropolis.

La historia mágina de Atenas. Barcelona:

Grijalbo.

Morris, AEJ. 2007. Historia de la forma urbana. Desde sus orígenes hasta la Revolución Industrial. Barcelona: Gustavo Gili.

Mosser, Monique Teyssot Geroges. 1990. L'architettura dei giardini d'Occidente. Milano: Electa.

Mumford, Lewis. 1966. La ciudad en la historia. Sus orígenes, transformaciones y perspectivas. Buenos Aires: Ediciones Infinito.

Peña Ganchegui, Luis. 1999. Premio Munibe. Vitoria/Gasteiz: Gobierno Vasco.

Salmerón, Pedro. 2006. La Alhambra. Estructura y paisaje. Córdoba: Almuzara.

Stierlin, Henri. 2006. Nuestra historia vista desde el cielo. Ciudadelas y fortalezas. Barcelona: Lunwerg.

Wilton-Ely, John. 1993. Piranesi as Architect and Designer. New York: The Pierpont Morgan Library. 